\title{
Using Gradebook in Blackboard
}

Samantha Parkes

I do not use technology in my classes for technology's sake. I am not that gifted with computers and some

things that are intuitive to others are a mystery to me. However, if I think it will make my life easier and help me become a more transparent teacher, then I will do my best to figure out new programs and devices. This is how I came to use the Gradebook feature of Blackboard in my classes and why I believe it has not only helped me to adapt to the AEC's grading system, but also has helped my students take a more active role in their own success in my courses.

\section{Background}

I was first exposed to Blackboard as an MA student and teacher at American University. Many of my professors used it to post our grades on papers, participation, and other assignments such as journals. I also taught a writing course for international graduate students and I posted their grades on Blackboard, just like the other professors. It was fairly simple because my course only had a few assignments and each one was worth a certain percentage of the overall grade.

Here is what the grade distribution looked like for my Academic Writing for International Graduate Students course at American University:

- $\quad$ Literature Review $10 \%$

- Major paper 25\%

- $\quad$ Reflection Paper $10 \%$

- Analytic Paper $10 \%$

- Action Plan 10\%

- $\quad$ Support System Paper 10\%

- Participation 25\% (punctuality, attendance, class participation, and in- class writing)

I could easily make a column for each assignment and weigh it for the percentage it represented in the course. This course was structured so that there were few assignments and I could easily check my math.

When I came to KU after spending an academic year in Nicaragua, I had very little time to wrap my brain around my own course material let alone put any grades into Blackboard. I kept track of all of my grades in a little book that I purchased with grid lines on it. I added the students' names and then each assignment with their score by hand. Then, at the end of the semester, I highlighted the in-class assignments in pink and the homework assignments in yellow and used a ruler to help me calculate the total points for each category.

After that, I had to meticulously add up the number of points for each student and divide by the total, and that is how I got the in-class and homework grades. Finally, I had to average those two grades to get the final grade. Looking back, I can now see several problems with this system:

Accuracy issues: I was constantly worried I had added up my grades incorrectly. What if the ruler slipped and I mixed up two students' scores? What if I typed incorrectly into the calculator? The possibility of human error was always nagging at my conscience. I double and sometimes triple checked my math to make sure I was giving students the correct grades. Of course, there was always a possibility that I had written down the wrong score to begin with.

Lack of transparency: Here I was, having just spent a year in Nicaragua teaching teachers to design clear prompts with clear evaluation criteria (see Parkes, 2013), and yet my students in the US did not know how their grades were being figured or even if they had been calculated correctly. I told them what their grade was for midterm, but they had no idea what their grades were throughout the semester. This led to problem 3.

Complaining about grades/Bargaining for higher grades: I found that students who do not know how they are doing are either blissfully unaware, or believe that they have the right to ask for a higher grade at the end of the semester. Whether this is sound logic on their part is not really the point because at some level, students have to be responsible for their grades in class and on homework, but I feel as though they have a right to know how they are doing at any point during the course. If they do not know what their grades are throughout the semester, and do not know how these grades are being calculated, how can I expect them to not challenge me at the end of the semester? 
Wasted Time: Not only did my pen and paper system make me second guess my math skills, it also took up a lot of time and as I discovered, grades are due very soon after the last day of class. There is often not enough time at the end of the semester to get all the grading done, let alone sit around highlighting and calculating grades by hand with a calculator and pencil.

\section{Discovery Process}

After trudging through my low tech grading process for a semester, I decided that something had to change and I knew I wanted to take advantage of the systems already set in place for me to use: namely Blackboard. At our Reading/Writing Level 3 launch meeting in spring 2013, our coordinator, Sandra Issa, gave us a breakdown of how she wanted the grades to be handled.

Figure 1. Grading Distribution for 034 Reading/Writing Spring 2013
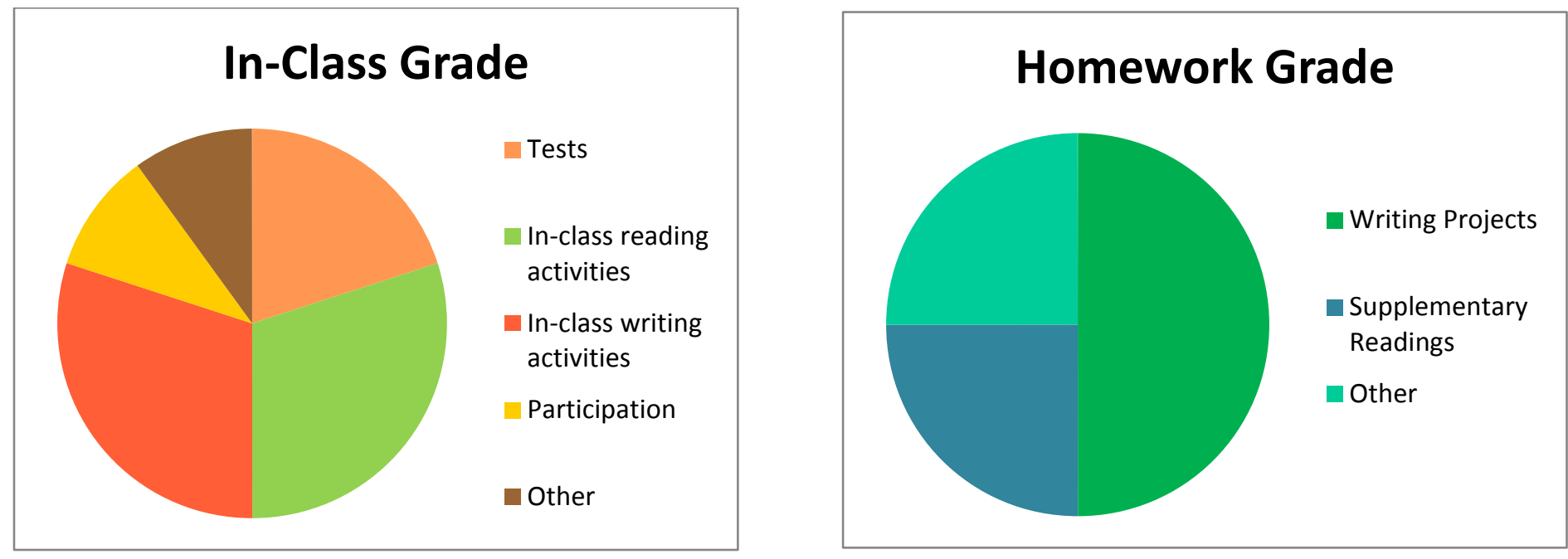

\section{In-Class Grade}

\section{$20 \% \quad$ Tests}

$30 \% \quad$ In-class reading activities

$30 \% \quad$ In-class writing activities

10\% Participation

$10 \%$ Other
Homework
$50 \% \quad$ Writing projects
$25 \% \quad$ Supplementary readings
$25 \%$ Other

Figure 1. Grade breakdown for Level 3 Reading/Writing. Grades are separated into in-class versus homework grades and the pie charts provide a visual representation of the grade distribution of various aspects of each portion of the grade.

I knew that I could enter grades into Blackboard using columns, but I was not sure how to set them up so they were weighted correctly. How could I get $50 \%$ of the grade to be homework and the other $50 \%$ to be in-class? Then, I needed to make it so that $30 \%$ of the in-class work had to be reading activities, and so on. I went to my computer and played around with my course a little. Then, I talked with others whom I knew to be great techno wizzes. After figuring out a framework for how to enter the grades, I called the Blackboard support people and explained to them what I was trying to do and how I thought I could do it. They assured me that I was on the right track and so I went about setting up my Gradebook. For my AECR-030 class, I used the categories I was given: Tests, In-Class Reading Activities, In-Class Writing Activities, Participation, In-Class Other, Writing Projects, Supplementary Readings, and Homework Other. Then, I set up a weighted column titled "In-Class" and filled it with those appropriate categories and their respective percentages (i.e. In-Class Reading=30\%). Next, I set up a weighted column titled "Homework" and filled it with the homework categories and percentages (i.e. Writing Projects=50\%). Last, I created another weighted column titled "Weighted Total" that would average the two other weighted columns: In-Class and Homework. 
Setting up your Gradebook may seem daunting, but once you figure out what kinds of assignments you will have for the class, (these become your categories in Blackboard) it is very easy and takes about five minutes. After you have laid a foundation, go about the business of entering assignments and grades throughout the semester. It can be updated whenever the instructor decides to enter grades. I entered scores as I graded assignments, but others may choose to do it once a week or whatever works best for the instructor and the course.

\section{Suggestions}

If you plan on updating your grades throughout the semester, I suggest teaching your students how to check their grades on Blackboard and asking them periodically to check and make sure everything looks correct. It is possible to enter something incorrectly or even forget to enter a grade, but diligent students will most likely notice this and let you know. This puts the onus on the students to be aware of how they are doing throughout the semester and will cut down on those awkward conversations at the end of the semester where students complain about their grades and offer to do any amount of extra credit to raise their grade because if executed properly, they will know what their in-class grade is and what their homework grade is already. Their grade will go up as they complete assignments successfully and it will go down if they miss an assignment or fail to perform well on exams. If they miss an assignment, they do not need to consult with the teacher, (“Teacher, did I miss anything important?"). They can simply look on Blackboard to see what the assignment is and how many points it is worth. The onus is on them to make up the work.

Most importantly, with this level of transparency, students will be able to diagnose their own strengths and weaknesses and have a better idea of what aspects of the course they need to improve. They might learn that doing well on tests, but not turning in homework results in a lackluster final grade. In addition, having a broad perspective of a student's performance in the course will give the instructor valuable information to use when conducting midterm conferences and preparing students' final grades. The information provided in the Gradebook will help students set realistic goals and the instructor can easily monitor students’ progress.

\section{Possible Drawbacks}

Even though this system has been effective for me, it may not be helpful for all teachers and situations. As with every system, program, or new piece of technology, there could be drawbacks. One of these is that it requires some time (and thought) to set up at the beginning of the semester. This most likely is not a problem for those of us teaching courses that have established curricula, or that we have taught before. However, if you are experimenting with a new course, and plan to flesh out the balance of points throughout the course of the semester, it might make it difficult to set up your gradebook. While Blackboard makes it easy to change percentages and points at any time, it might confuse your students if you have to make major adjustments in the middle of the semester.

Using this system also requires a fair amount of data entry throughout the semester so that students can see how various assignments affect their grades. This can be time consuming and there is also the potential to enter the wrong grade for the wrong student. However, I have found that if this occurs, students are all too happy to correct you.

Ultimately, there is a learning curve when working with new technology that requires time and patience. There is also the potential for technical issues beyond our control to corrupt or delete work. Printing off a report of the grades periodically is an insurance policy against potential technical issues, if one remembers to do it.

\section{Conclusions}

In the end, using the Gradebook function of Blackboard has made my life easier. I spend less time figuring grades and worrying if I have properly weighted each assignment. I can easily set standards for success in my courses and students always know where they stand. I am responsible for grading assignments and posting the grades in a timely manner, and they are responsible for making sure everything has been entered correctly and for improving their scores in the aspects where their performance is weak. In the end, we have become responsible to each other. Ultimately, I feel as though my students will be better prepared to succeed in their future courses at the AEC and beyond.

\section{Reference}

Parkes, S. (2013). Students have a right to know: Transparency in the teaching of writing. Issues in Language Instruction at the AEC 2(1), 34-35. 